\title{
Underground storage protect the quality of vegetable oil more than aboveground storage
}

\author{
Jin-Liang Deng ${ }^{1}$ \\ ${ }^{1}$ Henan University of Technology
}

June 10, 2020

\begin{abstract}
Abstract: Peanut and soybean oils were placed in stainless steel storage tanks in natural environment, static atmosphere tanks, added tertiary butyl hydroquinone (TBHQ) tanks, nitrogen-filled tanks and underground tanks were stored for 18 months. Acid value, peroxide value, fatty acid composition, tocopherols, phytosterols and the volatile flavor compounds were detected. The results indicated that underground storage (no nitrogen adjustment and no antioxidant added) was found to be the most appropriate method for maintaining the quality of peanut and soybean oils over time. Static atmosphere tanks caused the most pronounced losses of tocopherols, phytosterols, and the volatile flavor compounds in peanut and soybean oils. The acid value of the four peanut oils and four soybean oils did not exceed the Chinese GB/T 1534-2017 and GB 2716-2018 standard limit of 1.5 and $3.0 \mathrm{mg} \mathrm{KOH} / \mathrm{g}$. However, the peroxide value of peanut oil in static atmosphere tank, nitrogen-filled tank and underground tank exceeded the Chinese GB/T 1534-2017 standard limit of 12 meq O2/kg at 5 months, 11 months and 13 months respectively, but the peroxide value of peanut oil added TBHQ did not exceed the national standard limit. The peroxide value of soybean oil in static atmosphere tank and nitrogen-filled tank exceeded the Chinese GB 2716-2018 standard limit of 20 meq $\mathrm{O} 2 / \mathrm{kg}$ at 7 months and 18 months respectively, but the soybean oil added TBHQ and underground did not exceed the national standard limit.
\end{abstract}

\section{Underground storage protect the quality of vegetable oil more than aboveground storage} Jin-Liang ${ }^{1}$ Deng, Yu-Lan ${ }^{1}$ Liu,Guo-Hao Sun

College of Food Science and Technology, Henan University of Technology, Zhengzhou, 450001, China.

${ }^{*}$ Address correspondence to Yu-Lan Liu at School of Food Science and Technology, Henan University of Technology, Zhengzhou, 450001, China (E-mail: liuyl7446@sina.com; telephone: +86-13803715764).

Abstract: Peanut and soybean oils were placed in stainless steel storage tanks in natural environment, static atmosphere tanks, added tertiary butyl hydroquinone (TBHQ) tanks, nitrogen-filled tanks and underground tanks were stored for 18 months. Acid value, peroxide value, fatty acid composition, tocopherols, phytosterols and the volatile flavor compounds were detected. The results indicated that underground storage (no nitrogen adjustment and no antioxidant added) was found to be the most appropriate method for maintaining the quality of peanut and soybean oils over time. Static atmosphere tanks caused the most pronounced losses of tocopherols, phytosterols, and the volatile flavor compounds in peanut and soybean oils. The acid value of the four peanut oils and four soybean oils did not exceed the Chinese GB/T 1534-2017 and GB $2716-2018$ standard limit of 1.5 and $3.0 \mathrm{mg} \mathrm{KOH} / \mathrm{g}$. However, the peroxide value of peanut oil in static atmosphere tank, nitrogen-filled tank and underground tank exceeded the Chinese GB/T 1534-2017 standard limit of 12 meq $\mathrm{O}_{2} / \mathrm{kg}$ at 5 months, 11 months and 13 months respectively, but the peroxide value of peanut oil added TBHQ did not exceed the national standard limit. The peroxide value of soybean oil in static atmosphere tank and nitrogen-filled tank exceeded the Chinese GB 2716-2018 standard limit of 20 meq $\mathrm{O}_{2} / \mathrm{kg}$ at 7 months and 18 months respectively, but the soybean oil added TBHQ and underground did not exceed the 
national standard limit. Although adding TBHQ storage can protect the flavor of peanut oil, its harmful compounds counteract its positive effects. In contrast, nitrogen storage and underground storage are greener and safer. Underground tank storage will be a new oil storage technology to extend the shelf life of peanut and soybean oils.

Keywords: Peanut oil; Soybean oil; Headspace; TBHQ; Storage temperature; Gas chromatographyolfactometry.

\section{Abbreviations}

LCD, Liquid crystal display; TBHQ, Tertiary butylhydroquinone; AV, Acid value; PV, Peroxide value; FFA, Free fatty acid; HPLC, High performance liquid chromatography; GC, Gas chromatography; GC-O, Gas chromatography-olfactometry; SD, Standard deviation; ANOVA, Analysis of variance.

Practical applications: Experiments were carried out to study the possibility of improving the oxidation stability of peanut and soybean oils at industrial and market level. According to the preliminary results, it should be interesting to better explore the suitability of storing peanut and soybean oils in underground tanks.

\section{Introduction}

Soybean and peanut are the first and second most important sources of vegetable oils in the world and the major edible oil produced and consumed in China. The conservation of vegetable oils is a very complex operation, because, to maintain the quality level over time, it is necessary to take precautions to avoid increased acidity and the onset of rancidity caused by oxidation. The oxidation rate depends on a number of factors including the availability of oxygen, light and temperature [1].

To retard or prevent oxidative deterioration of vegetable oils, synthetic antioxidants, such as butylated hydroxyanisole (BHA), butylated hydroxytoluene (BHT) and tert-butyl hydroquinone (TBHQ) have widespread use as oil additives in many countries [2], a maximum amount of $200 \mathrm{mg} / \mathrm{kg}$ oil is allowed [3]. However, the safety of synthetic antioxidants and their decomposition products has been re-recognized and evaluated in recent years $[4,5]$. Recent reports reveal that these compounds may be implicated in many health risks [6,7]. Therefore, many countries banned their utilization. Until now, many experimental studies have been carried out to verify that nitrogen can improve the stability and the shelf life of oil, and slow down its oxidative changes. The use of nitrogen atmosphere and the reduction of the oxygen in the headspace volume can appreciably control quality changes of vegetable oil during storage time [8-12]. Moreover, the most significant factor affecting the vegetable oil quality is storage temperature [13-15]. Under high temperature conditions, even with nitrogen as the conditioning gas, this condition favors the increase in AV and the $\mathrm{K}_{270}$ value of vegetable oil [16]. The current vegetable oil storage technology is to prevent the main factors (oxygen, light, temperature). It is difficult to find a balance between oil quality and storage costs. There is a tendency to find new ways to replace existing storage technologies. In the other hand the new cultivars of high oleic peanuts ( $75-82 \%$ of oleic acid) were assayed for oxidation stability with a better results than conventional peanuts (43-50\% oleic acid) because the mayor proportion of oleic acid [17]. As very few studies were focused on the use of underground condition, where is a dark, low-temperature storage environment.

The goal of this work is to investigate the change in peanut and soybean oils quality, based on the analysis of such parameters as AV, PV, fatty acids, tocopherols, phytosterols and the volatile flavor compounds during different storage conditions (added TBHQ storage, nitrogen storage, underground storage) of stainless steel tanks. This work is to develop a preservation method that can maintain the high quality of peanut and soybean oils as long as possible, increasing its shelf life.

\section{Materials and methods}

Materials and chemicals

The refined peanut oil and degummed crude soybean oil were obtained from Kaifeng Longda Vegetable Oil Co. (China). The stainless steel oil storage tanks are manufactured by Henan Sun- 
shine Oil and Fats Co. (Zhengzhou, China). TBHQ was purchased from Guangdong Food Industry Research Institute (purity[?]99.0\%); fatty acid methyl ester standards, $\beta$-sitosterol (purity[?]99.0\%),stigmasterol(purity[?]95.0\%), campesterol $\quad$ (purity[?]99.5\%),Sitosterol(purity[?]99.0\%), $a$ -cholesterol (purity[?]95.0\%), N,O-bis-(trimethylsilyl)trifluoroacetamide (BSTFA) containing 1\% trimethylchlorosilane (TMCS) was purchased from Sigma-Aldrich (St. Louis, MO) and used without further purification; Tocopherols $(\alpha-, \beta-, \gamma-$ and $\delta$-) standards (purity[?]99.0\%)Sigma-Aldrich (St. Louis, MO). N-hexane, 1-Methylethanol were HPLC grade which were purchased from VBS (St. Louis, MO, USA), potassium hydroxide $(\mathrm{KOH})$, Chloroform $\left(\mathrm{CHCl}_{3}\right)$ and all other solvents and chemicals used in this study were of analytical grade and used without further purification.

Experimental design

A temperature real-time detection recorder is set up on the above ground tanks and the underground tanks. The analog data received from the temperature probes were converted to digital data by the YA200R recorder and stored in flash memory. The YA200R recorder has an LCD sensor status display for real-time visualization (Fig. 1).

Oil was mixed in a $800 \mathrm{~L}$ stainless steel tank and equally distributed to the four $200 \mathrm{~L}$ stainless steel tanks. The headspace volume was equal to $10 \%$ of the total volume of the each tank. Four different conditions: static atmosphere tank, added TBHQ tank, nitrogen-filled tank and underground tank.

Tank A and $\mathrm{E}$ was not filled with $\mathrm{N}_{2}$ and stored outdoors (static atmosphere tank) with peanut and soybean oil; Tank B and F was not filled with $\mathrm{N}_{2}$ and stored outdoors, but was added $0.02 \%$ TBHQ of oil weight storage (added TBHQ tank) with peanut and soybean oil; Tank C and $\mathrm{G}$ was was filled with $\mathrm{N}_{2}$ and stored outdoors (nitrogen-filled tank) with peanut and soybean oil; Tank D and $\mathrm{H}$ was was not filled with $\mathrm{N}_{2}$ but stored underground (underground tank) with peanut and soybean oil.

Analysis of fatty acid composition

Fatty acid methyl esters (FAMEs) were prepared according to the method [18] described by GC analysis was performed on an Agilent 7890B Gas Chromatograph (Agilent Technologies, USA), equipped with a flame ionization detector and a HP-88 capillary column (100 mnologies, $0.20 \mu \mathrm{m}$, Agilent Technologies, USA). The column temperature program was as follow: the initial column temperature was 140 , and it was maintained for $5 \mathrm{~min}$, and then from 140 to 240 at $4 / \mathrm{min}$, and held for $10 \mathrm{~min}$ at 240 . The injector temperature was 250 and the detector temperature was 280 . Nitrogen was used as the carried gas at a flow rate of 1.0 $\mathrm{mL} / \mathrm{min}$, and a split ratio of 50:1 was used. The fatty acids peaks were identified by comparison of retention times with those of standards. Fatty acid methyl esters were quantified as percentages of the total methyl ester peak areas. Eight fatty acids were considered in this study. They are palmitic acid $\left(\mathrm{C}_{16: 0}\right)$, stearic acid $\left(\mathrm{C}_{18: 0}\right)$, oleic acid $\left(\mathrm{C}_{18: 1}\right)$, linoleic acid $\left(\mathrm{C}_{18: 2}\right)$, linolenic acid $\left(\mathrm{C}_{18: 3}\right)$, arachidic acid $\left(\mathrm{C}_{20: 0}\right)$, behenic acid $\left(\mathrm{C}_{22: 0}\right)$ and tetracosanoic acid $\left(\mathrm{C}_{24: 0}\right)$ expressed as percentages of fatty acid methyl esters.

Analysis of phytosterol

The phytosterol content of the oils was determined following ISO 12228-1:2014 method [19] and was analyzed using gas chromatography (GC) system (Agilent, 7890, Santa Clara, U.S.A.), equipped with a flame ionization detector (FID). Separation of the sterols was performed using HP-5 column $(30 \mathrm{~m} \times 320 \mu \mathrm{m} \times 0.25$ $\mu \mathrm{m}$, Agilent J\&W Scientific, Santa Clara, U.S.A.). Further parameters were as follows: nitrogen as carrier gas; split injection (1:20) was used, and the injection volume was $1 \mu \mathrm{l}$; flow rate was $1.0 \mathrm{~mL} / \mathrm{min}$; oven temperature was held for $20 \mathrm{~min}$; injector temperature, ; detector temperature,. The compounds were quantified by adding an internal pattern ( $5 \alpha$-cholestanol). All samples were analysed in triplicate and the sterol/oil ratio was expressed in $\mathrm{mg} / 100 \mathrm{~g}$.

Analysis of tocopherols

$0.5 \mathrm{~g}$ of oil was dissolved in $10 \mathrm{~mL}$ of HPLC-grade $\mathrm{n}$-hexane, then filtered using a $0.45 \mu \mathrm{m}$ organic membrane filter for HPLC analysis. The analysis of tocopherols and tocotrienols were performed using a Waters e2695 
HPLC system equipped with a Waters 2475 fluorescence detector (Waters Corporation, Milford, USA) and an Elite NH2 column $(250 \mathrm{~mm} \times 4.6 \mathrm{~mm} \times 5 \mu \mathrm{m}$, Dalian Elite Analytical Co., Ltd, Dalian, China). The column temperature was $35{ }^{\circ} \mathrm{C}$, isopropanol and n-hexane $(1: 99, \mathrm{v} / \mathrm{v})$, flow rate $0.8 \mathrm{~mL} / \mathrm{min}$. The excitation wavelength was $298 \mathrm{~nm}$ and the emission wavelength was $325 \mathrm{~nm}$. The tocopherols and tocotrienols were identified by comparing their retention times with authentic standards and quantified based on the peak areas compared with the external standards. All samples were analysed in triplicate and the tocopherol/oil ratio was expressed in $\mathrm{mg} / \mathrm{kg}$.

Analysis of volatile flavor compounds

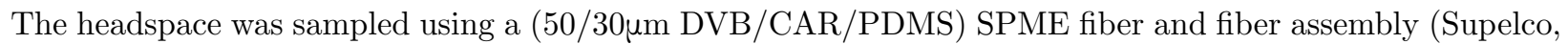
Inc., U.S.A.) for each peanut oil sample, allowing the fiber to equilibrate in the headspace of the 50-mL screw top vial heated by a water bath (Agilent, Santa Clara, U.S.A.) in order to acheive headspace equilibrium more quickly. Headspace equilibration of samples was determined by sampling the headspace using SPME over fixed periods of time. Equilibrium was reached after $30 \mathrm{~min}$ in a water bath. After the SPME fiber reached equilibrium, thermal desorption for $3 \mathrm{~min}$ in the injection port was required in order to remove all compounds on the fiber, as determined by preliminary studies. The volatile aroma compounds were analysed on Agilent 5977 Network-mass selective detector (MSD) equipped with an Agilent 7890B gas chromatograph (both Agilent Technologies, Inc., Palo Alto, CA, USA). Furthermore, The volatiles were separated by HP5MS (Agilent J\&W GC Columns., U.S.A.) Capillary Column ( $30 \mathrm{~m}$ length $\times 0.25 \mathrm{~mm}$ i.d. $\times 0.25 \mu \mathrm{m}$ thickness) . Flavor compounds were separated by increasing the temperature from ( 3 min hold time) to (8-min hold time), ramped at per min. Injection port temperatures were. The transfer line temperature was $240{ }^{\circ} \mathrm{C}$. The mass detector was operated at $230{ }^{\circ} \mathrm{C}$ in electron impact mode at $70 \mathrm{eV}$, and the ion source temperature was $230{ }^{\circ} \mathrm{C}$. The chromatograms were recorded by monitoring the total ion currents (TIC) in a mass range of $30-500 \mathrm{~m} / \mathrm{z}$. Qualitative and quantitative analysis: The mass spectrometry information of each component was matched and qualitatively matched with the NIST 17 mass spectrometer library, and only the results of positive and negative matching degrees greater than 80 (maximum 100) were reported. The volatile silane impurities contained in the instrument itself are removed, and the relative contents of the various compounds are calculated by the peak area normalization method.

Analysis of Gas chromatography-olfactometry (GC-O)

A GC-O analysis was performed on an gilent 7890B gas chromatograph equipped with a sniffing port (Sniffer 9000, Brechbühler Scientific Analytical Solutions Inc., Switzerland).

A Gerstel ODP-3 sniffing port using deactivated capillary column $(30 \mathrm{~cm} \times 0.3 \mathrm{~mm})$ heated at $200{ }^{\circ} \mathrm{C}$. This system which can obtain an MS signal for the identification and the odor characteristics of each compound detected by sniffing port at once. GC effluent was split 1:1 among the MSD and olfactometer via a switch. By smelling and recording the odour descriptions, 3 welltrained panellists performed the GC-O analysis. The perceived aroma intensity was evaluated and recorded by using the 1-9 scores. Each sample was sniffed twice by each panellist.

Physicochemical analysis

GB 5009.227-2016 [20] was used to determine the peroxide value (PV, milliequivalents oxygen (meq O2)/kg oil). GB 5009.299-2016 [21] was used to determine the acid value.

Statistical analysis

Statistical analysis each laboratory test on the oil was carried out in three replicates. Data were expressed as mean \pm sd. Variables were compared using one-way ANOVA. Data processing was performed using the data analysis and graphing software of Origin 9.0 and Microsoft Office Excel 2013, Hierarchical Cluster ananlysis (HCA) was finished by IBM SPSS Statistics software (version 20, SPSS, Inc., Chicago, IL).

\section{Results and discussion}

Changes in temperature 
Figure 2 shows the temperature levels measured by the sensors in the oil of the eight tanks for 18 months. During the storage period from February to April of the year, the average temperature of oil in aboveground tanks was lower than $20^{\circ} \mathrm{C}$, and the average temperature of oil in the summer from June to September was about $30{ }^{\circ} \mathrm{C}$, and the highest temperature was close to $40{ }^{\circ} \mathrm{C}$. While the average storage temperature of the oil in underground tanks at 12-20 throughout the year. Storage temperature is an important factor affecting the oxidative rancidity and overall quality of oils. Generally, for every $10 \mathrm{degC}$ increase in oil temperature, the oxidation rate will double [15]. The increase of temperature will also affect the minor components in oil [22].

Changes in the fatty acid composition

The fatty acid composition of peanut oils was determined using GC and listed in Table 2. It can be observed that five major fatty acids were present in peanut oils, which were $\mathrm{C}_{18: 1}(40 \%), \mathrm{C}_{18: 2}(39 \%), \mathrm{C}_{16: 0}$ (11 $\%), \mathrm{C}_{18: 0}(3 \%)$ and $\mathrm{C}_{22: 0}(3 \%)$. In a global study about fatty acids composition in peanuts the global average was of $43 \%$ of oleic acid and $35 \%$ of linoleic acid and the difference with respect to this result is that Chinese peanuts are more unstable with respect to global average [23]. Changes were found in the fatty acid composition during of 18 months stored, particularly in the composition of MUFAs and PUFAs in the oil samples. The fatty acids composition dose not change exceeding $0.6 \%$ of oil sample in tank A. The loss was due to intensive oxidation at natural temperature. However, only slight alteration in the composition of fatty acids (not exceeding $0.3 \%$ with reference to initial oil sample) was found in samples of tanks B, C, D. The above results are in confirmation with the findings of Wroniak et al [1], who reported PUFAs and MUFAs were significant $(p<0.05)$ reduced in stored oil samples, but only slight alteration in the composition of fatty acids (not exceeding $0.3 \%$ with reference to control oil sample) was found in samples exposed to oxygen and kept at room temperature (RT) after 12 months of storage of cold-pressed rapeseed oil. The fatty acid composition of soybean oil under various conditions was presented in Table 2 . It can be observed that five major fatty acids were present in soybean oils, which were $\mathrm{C}_{18: 2}(52 \%), \mathrm{C}_{18: 1}(24 \%), \mathrm{C}_{16: 0}(11$ $\%), \mathrm{C}_{18: 3}(8 \%)$ and $\mathrm{C}_{18: 0}(5 \%)$. Changes were found in the composition of MUFAs and PUFAs in the oil samples. The composition of fatty acids (not exceeding $0.3 \%$ with reference to initial oil sample) was found in samples of tank E. The loss was due to intensive oxidation at high natural temperatures. However, only slight alteration in the composition of fatty acids dose not exceeding $0.1 \%$ of oil samples in tank F, G, H.

Changes in tocopherol contents

The total content of tocopherols in control peanut oil sample was $467.3 \mathrm{mg} / \mathrm{kg}$ (Table 3). Results showed that tocopherols were significantly affected by the storage conditions. Based on the percentage of losses, the highest rate of tocopherols degradation was observed when oil was stored in tank A. Under such conditions, aboveground storage resulted in $20 \%$ loss of $a$-T, $62 \%$ loss of $\gamma$-T and $44 \%$ loss of $\delta$-T. When oil samples were stored in tank C, $a-\mathrm{T}, \gamma-\mathrm{T}, \delta-\mathrm{T}$ loss of $11 \%, 54 \%$ and $40 \%$ respectively. This phenomenon was due to contact of the oil with the oxygen present in the headspace of the tank, which promoted oxidative reactions of the tocopherols and thus their loss in the oil. Interestingly, negligible differences in percentage loss of tocopherols were observed in peanut oils of tank B and D, $2 \%$ and $3 \%$ loss of $a-\mathrm{T}, 53 \%$ and $51 \%$ loss of $\gamma$-T, $41 \%$ and $34 \%$ loss of $\delta$-T respectively. The least losse of tocopherols, and thus the highest tocopherols content was found in peanut oil samples, where the total tocopherols content left $347.8 \mathrm{mg} / \mathrm{kg}$ for peanut oil stored in tank D conditioned with air at underground average 18 after 18 months of storage, the percentage loss of the total tocopherols $25.6 \%$ (tank $\mathrm{D}$ ). When stored aboveground, the percentage loss of the total tocopherols increased to $38.9 \%$ (tank A), $27 \%$ (tank B), and $31.5 \%$ (tank C).

The total content of tocopherols in control soybean oil sample was $1525.4 \mathrm{mg} / \mathrm{kg}$ (Table 3). The least losse of tocopherols, and thus the highest tocopherols content was found in soybean oil samples, where the total tocopherols content left $1218.9 \mathrm{mg} / \mathrm{kg}$ for soybean oil stored in tank F conditioned with air and TBHQ added after 18 months of storage, and the percentage loss of the total tocopherols was $20.1 \%$, TBHQ had the best antioxidant effect on soybean oil. While the percentage loss of the total tocopherols increased to $42.7 \%$ (tank E), the loss of total tocopherols were due to intensive oxidation at high natural temperature. The above results are similar to those of Lee et al [24], who reported the degradation rates for tocopherols 
of $2.1 * 10^{3}$ and $8.9^{*} 10^{2} \%$ /day at 25 and 60 in soybean oil. The percentage loss of the total tocopherols increased to $24.5 \%$ (tank G). At the same time, the percentage loss of the total tocopherols only increased to $21.5 \%$ (tank $\mathrm{H})$.

Changes in phytosterol contents

The peanut oil contained a total of $263.31 \mathrm{mg} / 100 \mathrm{~g}$ phytosterols (Table 4). The following phytosterols have been determined in the analysed fresh oil sample: $\beta$-sitosterol, ca. $63 \%$, and campesterol, ca. $15 \%$, followed by sitosterol, ca. $12 \%$, while the content of stigmasterol was approximately $10 \%$ of total phytosterols. As can be seen from Table 4, the highest degradation rate of total sterols was found in tank A, when the tanks A was conditioned with air, the percentage loss of total sterols to $23.9 \%$, while for the oil stored in tank $\mathrm{C}$ conditioned with nitrogen-filled, the percentage loss of total sterols to $22.1 \%$. Respective loss of total sterols to $21.3 \%$ (tank B), When oil were stored in tank D, the percentage loss of total sterols to $16.9 \%$. In contrary to tocopherols, sterols showed high storage stability over the entire storage period [25]. This may be explained by the fact, that tocopherols were consumed first when protecting PUFAs from oxidation. The soybean oil contained a total of $358.01 \mathrm{mg} / 100 \mathrm{~g}$ sterols (Table 4). The following phytosterols have been determined in the analysed fresh oil sample: $\beta$-sitosterol, $54 \%$, and campesterol, $20 \%$, followed by stigmasterol, $18 \%$, while the content of sitosterol was approximately $7 \%$ of total phytosterols. As can be seen from Table 4, the highest degradation rate of total sterols was found in tank E, when the tank $\mathrm{E}$ were conditioned with air, the percentage loss of total sterols to $26.1 \%$, while for the oil stored in tank G conditioned with nitrogen, the percentage loss of total sterols to $24.1 \%$. Respective loss of total sterols in oil conditioned with adding TBHQ to $23.1 \%$ (tank F), When oil was stored in tank H conditioned with air under ground, the percentage loss of total sterols to $19.2 \%$.

Changes in the volatile compounds

Table 5 listed the identified volatile compounds of the peanut oil stored in the four tanks. A total of 64 volatile compounds were identified, which included 20 pyrazines, 17 aldehydes, 9 ketones, 8 alcohols, 3 acids, 2 furans, 2 pyrroles, 1 lactone, 1 phenol and 1 benzoquinone. During the 18 months experimental period, pyrazines showed a significant decrease with storage time. Pyrazines $36.42 \%$, as characteristic flavors of peanut oil, exhibited flavor characteristics of nutty and roasted aromas [26,27]. The loss of pyrazines in tank A peanut oil was the highest (content decreased to $16.33 \%$ ), and the content of pyrazines in tank B, C and D peanut oils were reduced to $21.92 \%, 27.02 \%$ and $29.08 \%$, respectively. Aldehydes showed a significant increase with storage time, and the content of aldehydes in tank A, B, C and D peanut oils were increased to $48.43 \%, 26.08 \%, 41.34 \%$ and $37.20 \%$, respectively. In particular, the content of hexanal as a characteristic of the oxidation degree of oil was significantly increased [28], the content of hexanal in the four peanut oils was $6.40,2.08,4.37$ and 2.10 times of the initial values, respectively. The peanut oil, in an accelerated oxidation test at $60^{\circ} \mathrm{C}$ showed that hexanal can reach values of $160 \mu \mathrm{g} / \mathrm{Kg}$ after 28 days affecting the sensory properties [29]. This showed that adding TBHQ storage, nitrogen-filled storage and underground storage played a decisive role in the preservation of peanut oil. The initial content of ketones, alcohols, acids and lipids of other small molecules are very small, and the content may be slightly increased or changed little during storage. It is speculated that these compounds have little effect on the flavor change during storage of peanut oil. It is worth noting that the tert-butyl p-benzoquinone, a volatile compounds formed by the oxidative decomposition of TBHQ [5], was detected in the peanut oil added TBHQ, and the content increased with the storage time. After storage for 18 months, its content accounted $22.55 \%$ for the total volatile compounds. Tert-butyl p-benzoquinone has certain toxicity $[6,7]$, affecting the safety of peanut oil. Therefore, although adding TBHQ storage can protect the flavor of peanut oil, its harmful compounds counteract its positive effects. In contrast, nitrogen storage and underground storage are greener and safer.

When GC-O method was used in evaluating the odour of the volatile compounds. 2,5-dimethylpyrazine and 2-methylpyrazine respectively showed nutty taste, roasted peanut flavor and nut aroma; benzaldehyde, furfural, phenylacetaldehyde and hexanal respectively showed bitter almond flavor, rotten grass flavor, sweet aroma and sour; 1-inch-3-ol, n-hexanol, n-pentanol and n-pentyl furan respectively give a mushroom flavor, a pungent taste, a grassy taste and a green bean flavor. The flavor wheel produced based on the sensory 
description of the GC-O sniffing of the main flavor compounds in peanut oil and the sensory evaluation score is shown in Fig. 3.

As the storage time prolonged, the overall flavor intensity of peanut oil gradually decreased. After 6 months of storage, the overall flavor, nutty flavor, baking flavor, sweet aroma and other strengths of the four peanut oils were significantly reduced, and the rancid taste was enhanced. In particular, the tank A peanut oil had the lowest overall flavor score and the highest rancid taste score; peanut oil has the highest overall flavor, nutty flavor, baking flavor and sweet aroma score, and has almost no rancid taste. The overall flavor score of tank B and C peanut oil is the same as that of tank D peanut oil. The nutty, baking and sweet flavor scores are slightly smaller than tank D peanut oil. This corresponds to the tendency of the volatile compounds of pyrazine in Table 5. It shows that nitrogen-filled tank, added TBHQ tank and underground tank can effectively delay the loss of peanut oil flavor compounds and achieve the purpose of quality preservation. After the storage time was extended to 18 months, the overall flavor, nutty flavor, baking flavor, and sweet flavor intensity of the four peanut oils decreased again, and the rancid taste was significantly enhanced. At this time, the characteristic flavor of the peanut oil was seriously lost, and the degree of rancidity was accelerated.

Changes in acid value (AV)

Figure 4a shows the trend in acidity levels for the peanut oil stored in the four tanks. The acid value of the four peanut oils increased slowly from February to April. After April, the acid values of the four peanut oils continued to increase with the increase of temperature. The acid value of peanut oil in tank A increased faster than others, and after storage in April of the following year, the acid values of the four peanut oils increased rapidly again with the temperature rising. The oil stored in tanks B and D showed a consistent trend, and the difference in acid value. This increase in acid value during the 18 months experimental period is lower than the increase for the oil in tank A and C. Statistical analysis indicated no significant differences $(p<0.05)$ in acidity for tanks B and D, However, tank A and C was significantly different from tanks B and D starting from the second month of storage. At the end of 18 months of storage, the acid value of four peanut oils stored in tank A, B, C and D increased from the initial 0.84 to $0.99,0.89$, and $0.97 \mathrm{mg} / \mathrm{g}$, respectively, according to GB/T 1534-2017 [30] of China, limited of peanut oil acid value (KOH) ever, tank $\mathrm{A}$ and $\mathrm{C}$ wvalue of the three peanut oils did not exceed the national standard limit.

Figure $4 \mathrm{~b}$ shows the trend in acidity levels for the soybean oil stored in the four tanks. The acid value of the four soybean oils increased with the storage time. The acid value of soybean oil stored in tank E increased more obviously. The oil stored in tanks F, G, and $\mathrm{H}$ showed a consistent trend, this increase in acid value during the 18 months experimental period is lower than the increase for the oil in tank E. At the end of 18 months of storage, the acid value of soybean oil stored in tank E, F, G and $\mathrm{H}$ increased from the initial 1.01 $\mathrm{mg} / \mathrm{g}$ to $1.47,1.36,1.38,1.34 \mathrm{mg} / \mathrm{g}$, according to GB 2716-2018 [31] of China, the limit value of soybean oil acid value $[?] 3 \mathrm{mg} / \mathrm{g}$. The acid value of the four soybean oils did not exceed the national standard limit.

Changes in peroxide value (PV)

Figure 5a showed the tendency of the PV for peanut oil stored in the four tanks. The PV increased as storage time increased, especially after April, the peroxide value increased sharply with the increase of oil temperature, from September to April, the oil temperature is lower, and the peroxide value is also relatively flat. After the next year April, the peroxide value increases sharply after the temperature rises. For the oil stored in tank A increased the most, an elevated increase of peroxide value was observed, with a starting value of 2.5 and a final value of 53.9. The oil in tanks $\mathrm{B}, \mathrm{C}$, and $\mathrm{D}$ showed a significantly lower peroxide after 18 months of storage, than the oil stored in tank A. When the tanks A were conditioned with air, the PV was higher than 12 meq $\mathrm{O}_{2} / \mathrm{kg}$ (limit value of the Chinese Standard) only 5 months, while the tank D was underground, the PV stayed within the limit value of the Standard for 12 months. Other study showed that PV can reach until 90 meq $\mathrm{O}_{2} / \mathrm{kg}$ in accelerated oxidation test during 28 days at $60^{\circ} \mathrm{C}$, but this value is for over the value limits for commercialization in the world, this PV affect the sensory performance with reject by consumers [29]. A significant difference $(p<0.05)$ was observed. While the average storage temperature 
of the tank $\mathrm{D}$ is only 18 . This important result shows that it is possible to improve the stability of peanut oil by replacing outdoor with underground storage. When the tank $\mathrm{C}$ was conditioned with nitrogen, the PV stayed within the limit value of the standard for 10 months. This confirms that the presence of nitrogen in the tank protects peanut oil from the oxidation process, even at outdoor temperature. When the tank $\mathrm{B}$ was conditioned with adding TBHQ, the peroxide value of peanut oil increased the least. The PV was lower than the limit value of the standard for 18 months of outdoor storage. It can be seen that TBHQ has the best antioxidant effect, the antioxidant effect of underground storage on peanut oil was second only to that of TBHQ. A strong correlation has been found between peroxides formation and the temperature of oil, leading to conclusion that the most critical factor affecting the rate of oxidation in the peanut oil is the high temperature.

Figure 5b showed the tendency of the PV for soybean oil stored in the four tanks. The PV increased as storage time increased. The tank $\mathrm{E}$ was significantly different from tanks $\mathrm{F}, \mathrm{G}$, and $\mathrm{H}$ starting from the third month of storage. For the oil stored in tank E, when the tank E were conditioned with air, an elevated increase of PV was observed, with a starting value of 2.9 and a final value of 65.6 , the PV was higher than 20 meq $\mathrm{O}_{2} / \mathrm{kg}$ (limit value of Chinese Standard) only 7 months. While the oil stored in tank $\mathrm{G}$ was significantly different from tank E, a low increase of PV was observed, with a starting value of 2.9 and a final value of 21.6, when the tank G was conditioned with nitrogen, the PV stayed within the limit value of the Standard for 18 months. This may be linked to the fact that the use of nitrogen atmosphere and the reduction of the oxygen in the headspace volume can appreciably control oxidation of soybean oil during storage time. Similar findings were stated by, who reported the oil stored under air showed a marked decrease of quality after only two months of storage, while the use of inert gases in the headspace of the container during storage can reduce the presence of oxygen and preserve the compositional, nutritional and organoleptic qualities of the oil. The trends were similar for tank $\mathrm{F}$ and $\mathrm{H}$, and the increase in PV was low, with a mean initial value of 2.9 and mean final value of 10.9, the PV was lower than the limit value of the standard for 18 months. No significant differences $(p<0.05)$ were observed among tank $\mathrm{F}$ and $\mathrm{H}$ for the duration of the experiment. While the average storage temperature of the tank $\mathrm{H}$ was only 18 . Other authors reported another indicator to make an easier comparison between different studies. The totox value combines $\mathrm{PV}$ and $p$-Anisidine value because they are complementary states of oxidation and the report is more comparable, but this indicator is not used in commercial scale [32].

\section{Chemometric analysis}

Hierarchical cluster ananlysis (HCA) was performed in order to observe similarities or dissimilarities or between the oil samples. The dissimilarities of different clusters was defined by the euclidean distance matrix and calculated by ward's method. The results of peanut oil were presented in a dendrogram structure (Fig. 6), showing three distinct clusters based on the threshoid value (811.76) with a high similarity between tank $\mathrm{B}$ and tank D (Dissimilarity coefficient $\mathrm{D}=264.97$ ). Whereas tank A and tank C presented two distinct clusters with a high dissimilarity $(\mathrm{D}=4326.86)$ between them and the other group of tanks.

The result of soybean oil was presented in a dendrogram structure (Fig. 7), showing three distinct clusters based on the threshoid value (3301.37) with a high similarity between tank $\mathrm{F}$ and tank $\mathrm{H}$ (Dissimilarity coefficient $\mathrm{D}=689.20)$. Whereas tank $\mathrm{E}$ and tank $\mathrm{G}$ presented two distinct clusters with a high dissimilarity $(\mathrm{D}=102456.51)$ between them and the other group of tanks.

\section{Conclusions}

Based on the above results the following conclusion may be drawn: the relative contribution of storage conditions studied to the retention of peanut and soybean oils nutrition can be ordered as follows: underground storage ¿added TBHQ storage ¿nitrogen storage ¿static atmosphere storage. Underground storage was able to ensure comparable retention of quality over 18 months of storage. Underground storage of peanut and soybean oils can replace nitrogen storage and TBHQ storage. Results obtained in this study confirmed that high temperature can cause a significant decrease in the quality of peanuts and soybean oils, especially combined with oxygen. Although adding TBHQ storage can protect the flavor of peanut oil, its harmful 
compounds counteract its positive effects. In contrast, nitrogen storage and underground storage are greener and safer.

\section{Acknowledgements}

This work was supported by the National Project in the 13th Five-Year [2016YFD0401405]. Thanks to the financial support of Henan University of Technology Design Institute. Thanks to the financial support of China Grain Storage Management Corporation.

\section{Conflict of interest statement}

No conflict of interest exits in the submission of this manuscript, and manuscript is approved by all authors for publication.

\section{References}

1. Wroniak, M. , \& R?Kas, A. (2016). Nutritional value of cold-pressed rapeseed oil during long term storage as influenced by the type of packaging material, exposure to light \& oxygen and storage temperature. Journal of Food Science and Technology, 53(2), 1338-1347.

2. Kiokias, S. , Varzakas, T. , \& Oreopoulou, V. (2008). In vitro activity of vitamins, flavonoids, and natural phenolic antioxidants against the oxidative deterioration of oil-based systems. Critical Reviews in Food Science and Nutrition, 48(1), 78-93.

3. Codex Alimentarius (2017a). standard for edible fats and oils not covered by individual standards. Codex stan, 19-1981.

4. Li, J. , Bi, Y. , Yang, H. , \& Wang, D. (2017). Antioxidative properties and interconversion of $\backslash$ r, tert $\backslash \mathrm{r}$, -butylhydroquinone and $\backslash \mathrm{r}$, tert $\backslash \mathrm{r}$, -butylquinone in soybean oils. Journal of Agricultural and Food Chemistry, acs.jafc.7b04517.

5. Zhang, Q. , Wan, C. , Wang, C. , Chen, H. , \& Qin, W. (2017). Evaluation of the non-aldehyde volatile compounds formed during deep-fat frying process. Food Chemistry, 243, 151-161.

6. Zia-ur- Rehman, Habib, F. , \& Shah, W. H. (2004). Utilization of potato peels extract as a natural antioxidant in soy bean oil. Food Chemistry, 85(2), 215-220.

7. Hou, D. (2003). Potential mechanisms of cancer chemoprevention by anthocyanins. Current Molecular Medicine, 3(2), -.

8. Leone, A., Romaniello, R., Zagaria, R., \& Tamborrino, A. (2014). Development of a prototype malaxer to investigate the influence of oxygen on extra-virgin olive oil quality and yield, to define a new design of machine. Biosystems Engineering, 118(1), 95-104.

9. Sionek, B. , Krygier, K. , Ukalski, K., Ukalska, J. , \& Amarowicz, R. (2013). The influence of nitrogen and carbon dioxide on the oxidative stability of fully refined rapeseed oil. European Journal of Lipid Science and Technology, 115(12), 1426-1433.

10. Stefanoudaki, E. , Williams, M. , \& Harwood, J. (2010). Changes in virgin olive oil characteristics during different storage conditions. European Journal of Lipid Science \& Technology, 112(8), 906-914.

11. Ferrari F, Vignali G. (2018). Modeling and Simulation of Nitrogen Injection in Olive Oil. International Journal of Food Engineering, 14(2), 0-13.

12. Yong, Z. , Yu, Z. , Ruiyang, Z. , \& Hui, W. (2018). Design of nitrogen sealing process for oil tank in vegetable oil plant. China Oils and Fats, 43(7), 149-153.

13. Pristouri, G. , Badeka, A. , \& Kontominas, M. G. (2010). Effect of packaging material headspace, oxygen and light transmission, temperature and storage time on quality characteristics of extra virgin olive 
oil. Food Control, 21(4), 0-418.

$14 \mathrm{Li}$, X. , Zhu, H. , Shoemaker, C. F. , \& Wang, S. C. (2014). The effect of different cold storage conditions on the compositions of extra virgin olive oil. Journal of the American Oil Chemists\" Society, 91(9), 1559-1570.

15. Farhoosh, R. , \& Hoseini-Yazdi, S. Z. (2013). Shelf-life prediction of olive oils using empirical models developed at low and high temperatures. Food Chemistry, 141(1), 557-565.

16. Giovacchino, L. D. , Mucciarella, M. R. , Costantini, N. , Ferrante, M. L. , \& Surricchio, G. (2002). Use of nitrogen to improve stability of virgin olive oil during storage. Journal of the American Oil Chemists' Society, 79(4), 339-344.

17. Olmedo, R. H., Ribotta, P. \& Grosso, N. R. (2018). Oxidative stability, affective and discriminative sensory test of high oleic and regular peanut oil with addition of oregano essential oil. Journal of Food Science and Technology, 55 (12), 5133-5141.

18. Zhang, Z. S., Wang, L. J., Li, D. , Jiao, S. S., Chen, X. D. , \& Mao, Z. H. (2008). Ultrasound-assisted extraction of oil from flaxseed. Separation and Purification Technology, 62(1), 192-198.

19. ISO 12228-1:2014 (2014). Determination of individual and total sterols contents gas chromatographic method-Part 1: Animal and vegetable fats and oils. Geneva: International Organization for Standardization.

20. GB 5009.227-2016 (2016). Determination of peroxide value in food. In National Standard of the People's Republic of China; National Health and Family Planning Commission of PRC.

21. GB 5009.229-2016 (2016). Determination of acid value in food. In National Standard of the People's Republic of China; National Health and Family Planning Commission of PRC.

22. Wei, F., Yang, M. , Zhou, Q., Zheng, C. , Peng, J. H. , \& Liu, C. S. , et al. (2012). Varietal and processing effects on the volatile profile of rapeseed oils. LWT - Food Science and Technology, 48(2).

23. Wang, M. L., Raymer, P., Chinnan, M., \& Pittman, R. N. (2012). Screening of the USDA peanut germplasm for oil content and fatty acid composition, Biomass and Bioenergy, 39, 336-343.

24. Lee, J., Lee, Y. , \& Choe, E. (2007). Temperature dependence of the autoxidation and antioxidants of soybean, sunflower, and olive oil. European Food Research and Technology, 226(1-2), 239-246.

25. Innosa, D., Ianni, A., Palazzo, F., Martino, F., Bennato, F. , \& Grotta, L., et al. (2019). High temperature and heating effect on the oxidative stability of dietary cholesterol in different real food systems arising from eggs. European Food Research and Technology.

26. Somoza, V. (2007). The maillard reaction in food and medicine. Molecular Nutrition \& Food Research, $51(4), 381-382$.

27. Baker, G. L., Cornell, J. A., Gorbet, D. W. , O'Keefe, S. F. , \& Talcott, S. T. (2006). Determination of pyrazine and flavor variations in peanut genotypes during roasting. Journal of Food Science, 68(1), 394-400.

28. Antonio Jimenez, Aguilera, M. P. , Gabriel Beltran, \& Uceda, M. (2006). Application of solid-phase microextraction to virgin olive oil quality control. Journal of Chromatography A, 1121(1), 140-144.

29. Olmedo, R. H., Ribotta, P. \& Grosso, N. R. (2018). Oxidative stability, affective and discriminative sensory test of high oleic and regular peanut oil with addition of oregano essential oil. Journal of Food Science and Technology, 55(12), 5133-5141.

30. GB/T 1534-2017 (2017). Peanut oil. In National Standard of the People's Republic of China; General Administration of Quality Supervision, Inspection and Quarantine of PRC; Standardization Administration of PRC.

31. GB 2716-2018 (2018). National food safety standards: vegetable oil. In National Standard of the People's Republic of China; National Health and Family Planning Commission of PRC. 
32. Olmedo, R. H. \& Grosso, N. R. (2019) Oxidative Stability, Affective and Descriptive Sensory Properties of Roasted Peanut Flavored with Oregano, Laurel, and Rosemary Essential Oils as Natural Preservatives of Food Lipids. European Journal of Lipid Science and Technology, 121, 1800428.

\section{Figure Captions}

Fig. 1 Storage system.

Fig. 2 Temperature measured of oil in tanks.

Fig. 3 The flavor wheel of sensory evaluation score for peanut oil in tanks.

-e-, initial oil; -a-, 6 months of tank A; -b-, 6 months of tank B; -c-, 6 months of tank C; -d-, 6 months of tank $\mathrm{D} ;-\mathrm{A}-, 18$ months of tank A; -B-,18 months of tank B; -C-,18 months of tank D.

Fig. 4 Acid value trends for peanut and soybean oils in tanks.

Fig. 5 Peroxide value trends for peanut and soybean oils in tanks.

Fig. 6 Hierarchical Cluster ananlysis (HCA) dendrogram of peanut oil in tanks.

Fig. 7 Hierarchical Cluster ananlysis (HCA) dendrogram of soybean oil in tanks.

\section{Hosted file}

Responses to Editor and reviewers-U.doc available at https://authorea.com/users/332066/ articles/458528-underground-storage-protect-the-quality-of-vegetable-oil-more-thanaboveground-storage

\section{Hosted file}

Tables-U.docx available at https://authorea.com/users/332066/articles/458528-undergroundstorage-protect-the-quality-of-vegetable-oil-more-than-aboveground-storage

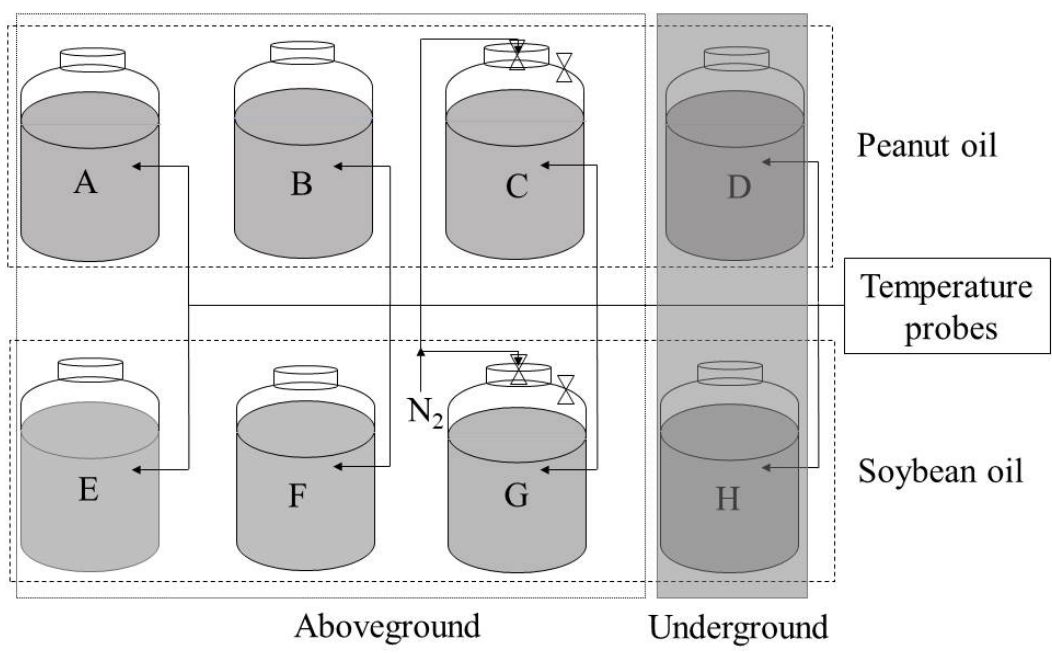



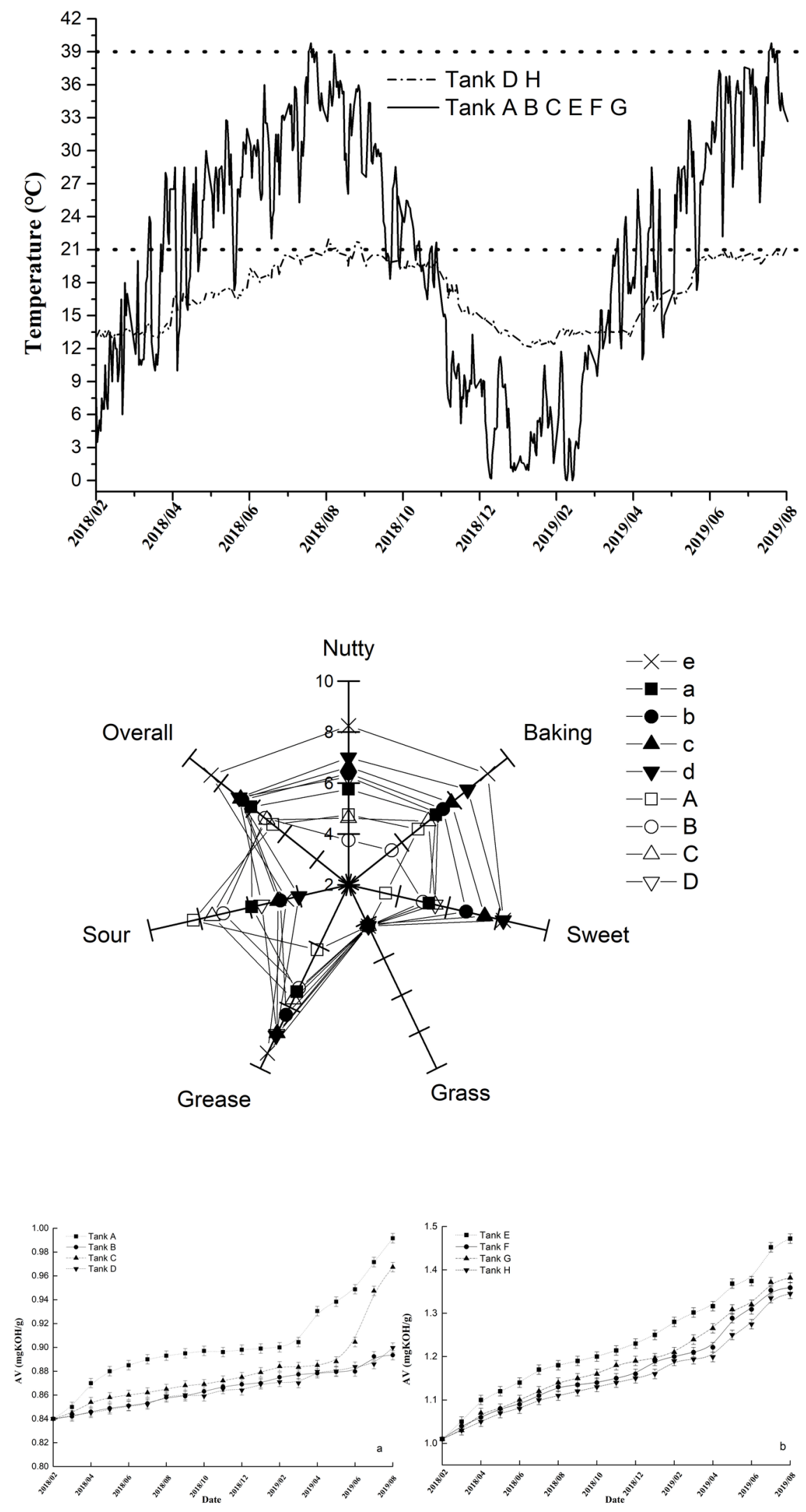

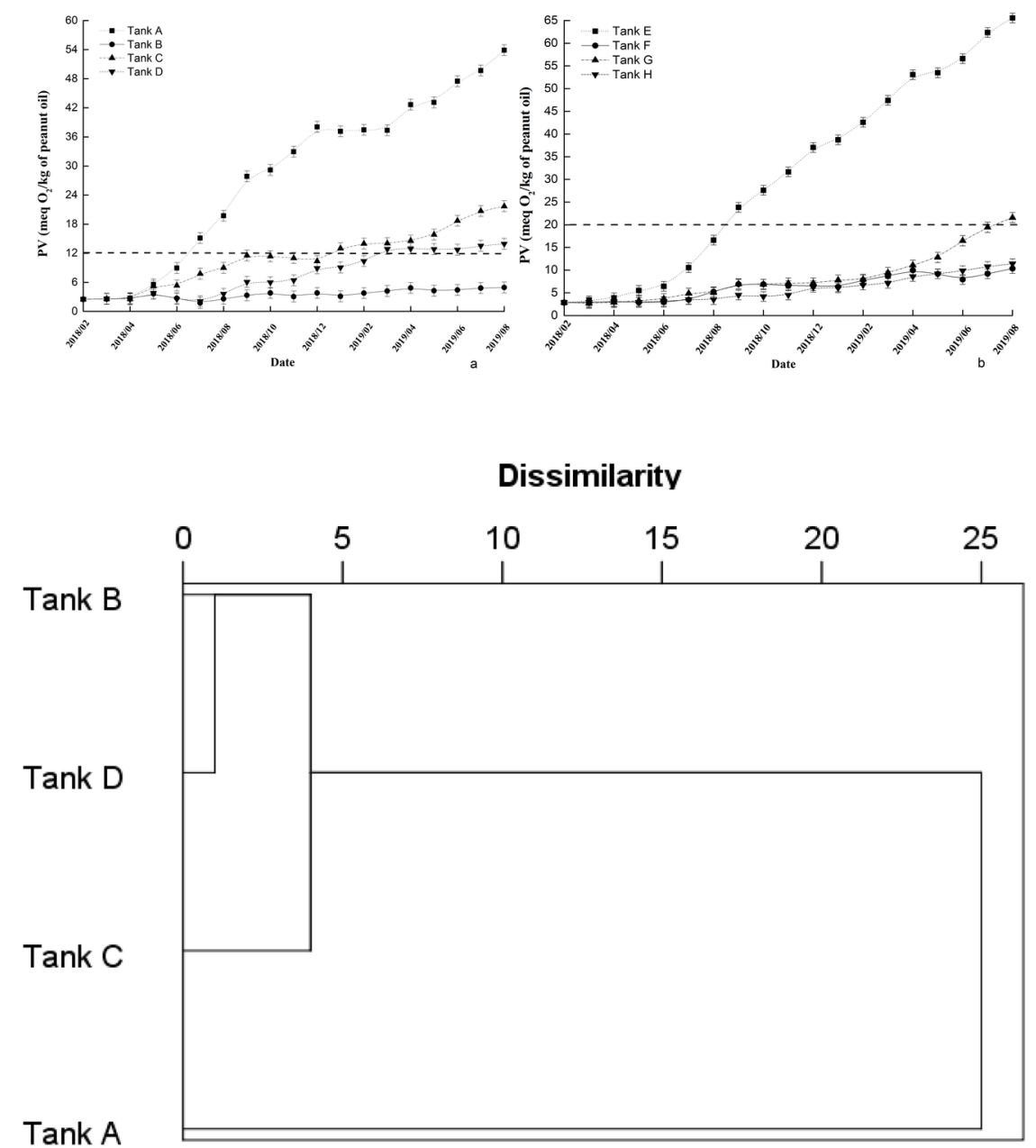




